Pacific Journal of Mathematics

ON SOME MEAN VALUES ASSOCIATED WITH A RANDOMLY 


\section{ON SOME MEAN VALUES ASSOCIATED WITH A RAN- DOMLY SELECTED SIMPLEX IN A CONVEX SET}

\section{H. GROEMER}

For any convex body $K$ in euclidean $n$-space denote by $m(K)$ the mean value of the volume of a simplex with vertices at $n+1$ randomly selected points from $K$. It is shown that among all convex bodies of given volume the mean value $m(K)$ is minimal if and only if $K$ is an ellipsoid. Actually, a more general result is obtained which shows that the higher order moments of the volume of a randomly selected simplex in a convex set have similar minimal properties.

Throughout this paper $R^{n}$ denotes euclidean $n$-space, where $n$ is a given fixed positive integer. A compact convex subset of $R^{n}$ which has interior points will be called a convex body. The volume of a convex body $X$ will be denoted by $v(X)$. If $p_{1}, p_{2}, \cdots, p_{n+1}$ are $n+1$ points of $R^{n}$ we write $C\left(p_{1}, p_{2}, \cdots, p_{n+1}\right)$ to denote the convex hull of the points $p_{1}, p_{2}, \cdots, p_{n+1}$. Including various forms of degeneracy, $C\left(p_{1}, p_{2}, \cdots, p_{n+1}\right)$ will be called a simplex with vertices at $p_{1}, p_{2}, \cdots, p_{n+1}$.

Let $\mathrm{K}$ be a given convex body. If $x_{1}, x_{2}, \cdots, x_{n+1}$ are $n+1$ points from $K$ the volume of the simplex with vertices at $x_{1}, x_{2}, \cdots, x_{n+1}$ is given by $v\left(C\left(x_{1}, x_{2}, \cdots, x_{n+1}\right)\right)$ and, assuming that the points $x_{1}, x_{2}, \cdots, x_{n+1}$ are variable, the mean value of this volume is defined by

$$
m(K)=(1 / v(K))^{n+1} \int_{x_{1} \in K} \cdots \int_{x_{n+1} \in K} v\left(C\left(x_{1}, \cdots, x_{n+1}\right)\right) d x_{1} \cdots d x_{n+1} \cdot
$$

Since $v\left(C\left(x_{1}, x_{2}, \cdots, x_{n+1}\right)\right.$ is a continuous function in the space $R^{n(n+1)}$ and since the set defined by the $n+1$ conditions $x_{i} \in K(i=1,2, \cdots, n+1)$ is a compact convex set in $R^{n(n+1)}$ it is obvious that $m(K)$ exists for every convex body $K$.

Blaschke [1], [2] has proved that for convex bodies in $R^{2}$ of given volume (i.e., area) the mean value $m(K)$ is minimal if and only if $K$ is an ellipse. See also Klee [11] for the history of this problem. Kingman [10] has conjectured that for any dimension $n$ and fixed volume $v(K)$ the minimum of $m(K)$ is reached if $K$ is a (solid) sphere in $R^{n}$. In addition, he pointed out that the higher order moments of the expected volume, i.e., the expressions

$$
m_{r}(K)=(1 / v(K))^{n+1} \int_{x_{1} \in K} \cdots \int_{x_{n+1} \in K}\left(v\left(C\left(x_{1}, \cdots, x_{n+1}\right)\right)\right)^{r} d x_{1} \cdots d x_{n+1}
$$

are of interest. The definitions (1) and (2) show that $m_{1}(K)=m(K)$. 
Just as before, it is seen that $m_{r}(K)$ exists for every convex body $K$ and every $r \geqq 0$. It is also clear that $m_{r}(K)$ is invariant under volume preserving affine transformation.

The main purpose of this paper is to provide a proof of Kingman's conjecture and of a similar but more general statement for the higher order moments. The following theorem contains the precise formulation of our result.

THEOREM. For any convex body $K$ in $R^{n}$ and any real number $r$ with $r \geqq 1$ the moments $m_{r}(K)$ satisfy the inequality

$$
m_{r}(S) \leqq m_{r}(K)
$$

where $S$ is a solid sphere in $R^{n}$ which has the same volume as $K$. Equality holds if and only if $K$ is an ellipsoid.

Because of $m_{1}(K)=m(K)$ this theorem has the following corollary as an obvious consequence.

CoROllary 1. Among all convex bodies of given volume the mean value $m(K)$ of the volume of a simplex with vertices at $n+1$ randomly selected points from the convex body $K$ is minimal if and only if $K$ is an ellipsoid.

Kingman [10] has been able to find an explicit formula for $m(K)$ in the case when $K$ is an ellipsoid of $R^{n}$, namely

$$
m(K)=2^{n}\left(\begin{array}{c}
n+1 \\
\frac{1}{2}(n+1)
\end{array}\right)^{n+1}\left(\begin{array}{c}
(n+1)^{2} \\
\frac{1}{2}(n+1)^{2}
\end{array}\right)^{-1} v(K) .
$$

Corollary 1 is related to a problem which, in two dimensional space, is frequently referred to as Sylvester's problem (cf. Kendall and Moran [9]). If $n+2$ points of $R^{n}$ are selected at random from a convex body $K$ the problem consists of finding the probability, say $P(K)$, that none of these $n+2$ points is in the interior of their convex hull. A simple calculation shows that (see Kingman [10])

$$
P(K)=1-\frac{(n+2) m(K)}{v(K)} .
$$

It follows that Corollary 1 is equivalent with the following statement.

Corollary 2. For any convex body $K$ of $R^{n}$ the probability $P(K)$ that the convex hull of $n+2$ randomly selected points from $K$ con- 
tains none of these points in its interior is maximal if and only if $K$ is an ellipsoid.

Similarly as the proof given by Blaschke for $n=2, r=1$ our proof of the above theorem depends on a property of the Steiner symmetrization of a convex body and on a certain characterization of ellipsoids. Since this characterization, which is of independent interest, appears to have been investigated only in the cases $n=2$ and $n=3$ (see Bonnesen and Fenchel [4], p. 143) we supply a new proof which imposes no restriction on the dimension or regularity of the convex body (Lemma 2).

First, we prove a lemma which shows that there exist convex bodies which have the desired minimal property with respect to $m_{r}(K)$.

LEMMA 1. If $r$ is a given positive number there exists a convex body $K_{0}$ in $R^{n}$ such that $v\left(K_{0}\right)=1$ and

$$
m_{r}\left(K_{0}\right) \leqq m_{r}(K)
$$

for every convex body $K$ with $v(K)=1$.

Proof. For every convex body $K$ there exist, according to a theorem of John [8], two ellipsoids $E, E^{\prime}$ such that $E^{\prime} \subset K \subset E$ and $v(E) \leqq n^{n} v\left(E^{\prime}\right)$. Because of $v\left(E^{\prime}\right) \leqq v(K)$ this implies $v(E) \leqq n^{n} v(K)$. It follows that to any $K$ with $v(K)=1$ there is a volume preserving affine transformation $\sigma$ such that $\sigma K \subset B$, where $B$ is a sphere of volume $n^{n}$ and center at the origin of the coordinate system. Because of this fact and because of the invariance of $m_{r}$ under volume preserving affine transformations it is evident that it suffices to prove (3) under the additional assumptions that $v(K)=1$ and $K \subset B$. Let us denote by $\mathscr{K}$ the class of all convex bodies for which these two conditions are satisfied. If a number $\mu$ is defined by

$$
\mu=\inf m_{r}(K) \quad(K \in \mathscr{K})
$$

then $\mu$ has obviously the property that for every $K \in \mathscr{K}$

$$
\mu \leqq m_{r}(K)
$$

and that there exists a sequence $K_{1}, K_{2}, \cdots$ of convex bodies in $\mathscr{K}$ such that

$$
\lim _{i \rightarrow \infty} m_{r}\left(K_{i}\right)=\mu .
$$

Because of $K_{i} \subset B$ the selection theorem of Blaschke can be applied to the class of convex bodies $K_{i}$. This justifies the assumption that 
the sequence $K_{1}, K_{2}, \cdots$ converges (in the Hausdorff-Blaschke metric) to some convex set $K_{0}$. Note that $K_{i} \in \mathscr{K}$ implies $K_{0} \in \mathscr{K}$.

The functional $m_{r}$ is obviously translation invariant, monotone and homogeneous in the sense that $m_{r}(s K)=s^{n \cdot r} m_{r}(K)$ for any $s \geqq 0$. It is known that such a functional is also continuous (cf. Hadwiger [7], p. 204 and the proof of the continuity of the volume in Blaschke [3], p. 61 or Eggleston [6], p. 72). Therefore, the convergence of $K_{i}$ to $K_{0}$ implies

$$
\lim _{i \rightarrow \infty} m_{r}\left(K_{i}\right)=m_{r}\left(K_{0}\right)
$$

Since (3) is an immediate consequence of (4), (5), and (6) the proof of the Lemma is finished.

$K_{0}$ will be referred to as a minimum body for $m_{r}$. Actually, $K_{0}$ does not depend on $r$ if $r \geqq 1$; but this cannot be concluded from our proof of Lemma 1.

For the formulation of our next lemma it is convenient to call a subset of $R^{n}$ flat if it is contained in some plane. It should be noted that in this paper a plane is always understood to be a hyperplane. As a further notational simplification the following concept will be used. If $K$ is a convex body and if $G$ is a line in $R^{n}$ we denote by $\mathscr{P}(K, G)$ the set of midpoints of all line segments of the form $X \cap K$ where $X$ ranges over all lines that are parallel to $G$ and meet $K . \mathscr{P}(K, G)$ will be called a midpoint set of $K$.

Lemma 2. A convex body $K$ is an ellipsoid if and only if the midpoint set $\mathscr{P}(K, G)$ is flat for every line $G$ of $R^{n}$.

Proof. If $K$ is a sphere the midpoint set $\mathscr{P}(K, G)$ is obviously flat for every line $G$. Applying an affine transformation the same result is seen to be true for ellipsoids.

Assume now that for a given convex body $K$ the midpoint set $\mathscr{P}(K, G)$ is flat for every line $G$. Let $H$ be any plane, and choose a coordinate system in $R^{n}$ which has the property that $H$ is given by $H=\left\{\left(x^{1}, x^{2}, \cdots, x^{n}\right) \mid x^{n}=0\right\}$. Then, if $G$ is a line that is orthogonal to $H$, the equation of the plane which contains $\mathscr{P}(K, G)$ can be written in the form

$$
x^{n}=a_{0}+a_{1} x^{1}+\cdots+a_{n-1} x^{n-1} .
$$

The symmetrization of $K$ with respect to the plane $H$ is achieved by mapping each point $\left(p^{1}, p^{2}, \cdots, p^{n}\right)$ of $K$ onto the point

$$
\left(p^{1}, p^{2}, \cdots, p^{n-1}, p^{n}-\left(a_{0}+a_{1} p^{1}+\cdots+a_{n-1} p^{n-1}\right)\right) .
$$

This mapping is obviously an affine transformation. Hence, one can 
conclude that every symmetrization is a volume preserving affine transformation, provided that the midpoint set $\mathscr{P}(K, G)$ is flat for every line $G$ of $R^{n}$.

The convex body obtained from $K$ by symmetrization with respect to a plane $H$ will be denoted by $\widetilde{K}(H)$.

It is known (see Danzer, Laugwitz, and Lenz [5]) that there is an ellipsoid, say $L$, which contains $K$ and has smallest possible volume. It is also known (see Hadwiger [7], p. 170) that there is a sequence of planes, say $H_{1}, H_{2}, \cdots$, in $R^{n}$ such that the sequence of convex bodies which is defined by $K_{1}=K, K_{i+1}=\widetilde{K}_{i}\left(H_{i}\right)(i=1,2, \cdots)$ contains a subsequence that converges to a sphere $S$. It follows that there are volume preserving affine transformations $\sigma_{1}, \sigma_{2}, \cdots$ such that the sequence $\sigma_{1} K, \sigma_{2} K, \cdots$ converges to $S$. If $K=L$ the proof of the lemma is obviously finished. Let us assume that $K \neq L$. In this case we have

$$
v(K)=v(S)<v(L) .
$$

Since the sequence $\sigma_{1} K, \sigma_{2} K, \cdots$ converges to $S$ there exists for any positive $\varepsilon$ an index $h$ such that

$$
\sigma_{h} K \subset S^{\varepsilon} .
$$

Here, $S^{\varepsilon}$ denotes the parallel domain of $S$, which, in this case is a sphere of radius $r+\varepsilon$ if $S$ has radius $r$. Because of (7) $\varepsilon$ can be taken so small that

$$
v\left(S^{\varepsilon}\right)<v(L) .
$$

(8) implies that the ellipsoid $\sigma_{h}^{-1} S^{\varepsilon}$ contains $K$, and (9) shows that $v\left(\sigma_{h}^{-1} S^{\varepsilon}\right)<v(L)$. However, according to the definition of $L$ it is impossible that an ellipsoid which contains $K$ has smaller volume than $L$. It follows that the trivial case $K=L$ is the only possiblility.

Lemma 3. Let $G_{1}, G_{2}, \cdots, G_{n+1}$ be $n+1$ distinct lines in $R^{n}$ which are of the form $G_{k}=\left\{\left(c_{k}^{1}, c_{k}^{2}, \cdots, c_{k}^{n-1}, z_{k}\right) \mid-\infty<z_{k}<\infty\right\}$. Assume that to each $G_{k}$ there corresponds an interval $I_{k}$ of the form $I_{k}=\left\{\left(c_{k}^{1}, c_{k}^{2}, \cdots, c_{k}^{n-1}, z_{k}\right)|| z_{k}-p_{k} \mid \leqq l_{k}\right\}$ where $l_{k}>0$. Write $z=$ $\left(z_{1}, z_{2} \cdots, z_{n+1}\right), p=\left(p_{1}, p_{2}, \cdots, p_{n+1}\right), e=(1,1, \cdots, 1), c^{j}=\left(c_{1}^{j}, c_{2}^{j}, \cdots, c_{n+1}^{j}\right)$ and

$$
D(z)=\frac{1}{n} \operatorname{det}\left(e, c^{1}, c^{2}, \cdots, c^{n-1}, z\right) .
$$

Finally, if $r$ is a given real number with $r \geqq 1$ write

$$
M(p)=\int_{\left|z_{k}-p_{k}\right| \leqq l_{k}}|D(z)|^{r} d z
$$


Then, if the numbers $c_{k}^{j}$ and the interval lengths $l_{k}$ are fixed, $M(p)$ attains its absolute minimum value exactly for those vectors $p$ for which all the midpoints $\left(c_{k}^{1}, c_{k}^{2}, \cdots, c_{k}^{n-1}, p_{k}\right)$ of the intervals $I_{k}(k=$ $1,2, \cdots, n+1)$ are contained in some plane of $R^{n}$.

Proof. Since $D(z)$ is a linear function of $z(10)$ can be written in the form

$$
M(p)=\int_{\left|u_{k}\right| \leqq l_{k}}|D(u)+D(p)|^{r} d u
$$

where $u=\left(u_{1}, u_{2}, \cdots, u_{n+1}\right)$ and $u=z-p$. If $p$ varies over the total $R^{n+1}$ the linear function $D(p)$ takes on any value between $-\infty$ and $\infty$. Therefore, a comparison of (11) with the function

$$
\mathrm{F}(y)=\int_{\left|u_{k}\right| \leqq l_{k}}|D(u)+y|^{r} d u
$$

shows that $M(p)$ and $F(y)$ have the same greatest lower bound. If all $y$-values for which $F(y)$ is (absolutely) minimal are known, the set of all vectors $p$ for which $M(p)$ is minimal are found by solving the linear equation

$$
y=D(p)
$$

for each such known $y$-value.

Now, to investigate the minimum value of $F(y)$ we note that $D(u)=-D(-u)$ implies

$$
\int_{\left|u_{k}\right| \leqslant l_{k}}|D(u)+y|^{r} d u=\int_{\left|u_{k}\right| \leqslant l_{k}}|D(u)-y|^{r} d u .
$$

This, together with the definition (12), shows that

$$
\begin{aligned}
& F(y)-F(0) \\
= & \frac{1}{2} \int_{\left|u_{k}\right| \leqq l_{k}}\left(|D(u)+y|^{r}+|D(u)-y|^{r}-2|D(u)|^{r}\right) d u .
\end{aligned}
$$

Since for a fixed value of $r(r \geqq 1)$ the function $|\zeta|^{r}$ is convex it follows that the integrand in (14), say $T(u, y)$, has the property that for all values of $u$ and $y$

$$
T(u, y) \geqq 0 \text {. }
$$

(The convexity of the function $|\zeta|^{r}$, i.e., the relation $\left|\left(\zeta_{1}+\zeta_{2}\right) / 2\right|^{r} \leqq$ $\left(\left|\zeta_{1}\right|^{r}+\left|\zeta_{2}\right|^{r}\right) / 2$, is a special case of Hölder's inequality $|\alpha a+\beta b| \leqq$ $\left(|\alpha|^{p}+|\beta|^{p}\right)^{1 / p}\left(|a|^{q}+|b|^{q}\right)^{1 / q}$, namely the case $\alpha=\beta=1 / 2, a=\zeta_{1}, b=$ $\left.\zeta_{2}, p=r / r-1, q=r\right)$. In addition to (15) it is clear that for $y \neq 0$ 


$$
T(0, y)=2|y|^{r}>0 \text {. }
$$

Because of the continuity of $T(u, y)$ as a function in $u$ (16) implies that for a given value of $y$ with $y \neq 0$ the inequality

$$
T(u, y)>0
$$

holds not only for $u=0$ but for a whole interval with center at $u=0$. From (14), (15), and (17) it follows that for any $y \neq 0$

$$
F(y)>F(0) \text {. }
$$

Hence, $F(y)$ attains an absolute minimum value at $y=0$ and nowhere else. This result in conjunction with (13) shows that $M(p)$ is minimal if and only if $D(p)=0$. Since $D(p)$ is the volume of a simplex with vertices at the points $\left(c_{k}^{1}, c_{k}^{2}, \cdots, c_{k}^{n-1}, p_{k}\right)$ we find finally that these points are contained in a plane if and only if $M(p)$ is minimal.

Proof of the Theorem. Since it has already been pointed out that $m_{r}(K)$ is a homogeneous function of $K$ it suffices to prove the Theorem under the assumption $v(K)=1$.

As before, let $H$ be the plane $\left\{\left(x^{1}, x^{2}, \cdots, x^{n}\right) \mid x^{n}=0\right\}$. Assume that $G_{1}, G_{2}, \cdots, G_{n+1}$ are $n+1$ given lines which are orthogonal to $H$ and have the property that each $G_{l}$ intersects $K$ in a line segment $I_{k}$ of positive length $l_{k}$. The midpoint of $I_{k}$ will again be denoted by $\left(c_{k}^{1}, c_{k}^{2}, \cdots, c_{k}^{n-1}, p_{k}\right)$. Under these assumptions the number $M(p)$ can be defined by (11). However, since in this case the vector $p$ is completely determined if $K$ and $G_{1}, G_{2}, \cdots, G_{n+1}$ are given we write now $M\left(K ; G_{1}, G_{2}, \cdots, G_{n+1}\right)$ instead of $M(p)$. Let $\widetilde{K}=\widetilde{K}(H)$ be the convex body which is obtained from $K$ by symmetrization with respect to the plane $H$. Since all the segments $\widetilde{K} \cap G_{k}$ have midpoints that are contained in a plane, namely $H$, Lemma (3) shows that

$$
M\left(\widetilde{K} ; G_{1}, G_{2}, \cdots, G_{n+1}\right) \leqq M\left(K ; G_{1}, G_{2}, \cdots, G_{n+1}\right)
$$

where equality holds if and only if the midpoints of the segments $K \cap G_{k}$ are already contained in some plane. Assume now that $K$ is a minimum body for $m_{r}$ and that $K$ is not an ellipsoid. Then Lemma 2 shows that there is a line $G$ such that the midpoint set $\mathscr{P}(K, G)$ is not flat. This implies obviously that $\mathscr{P}(K, G)$ contains $n+1$ points which are not contained in a plane of $R^{n}$. A simple continuity argument shows further that one may assume that the line segments corresponding to these $n+1$ midpoints have positive lengths. A suitable selection of the coordinate system permits us to assume that the plane $H=\left\{\left(x^{1}, x^{2}, \cdots, x^{n}\right) \mid x^{n}=0\right\}$ is orthogonal to $G$. Hence, if $G_{1}, G_{2}, \cdots, G_{n+1}$ is any system of $n+1$ lines that are parallel to $G$ 
and meet $K$ in intervals of positive lengths one obtains (18) and the additional information that strict inequality holds for at least one such system of $n+1$ lines.

Denote now by $K_{H}$ the projection of $K$ onto the plane $H$. Further, if $w_{k}$ is a point of $K_{H}$ denote by $G\left(w_{k}\right)$ the line which is orthogonal to $H$ and contains $w_{k}$. Using the definitions (2) and (10) an obvious rearrangement of the order of integration shows that

$$
=\int_{w_{1} \in K_{H}} \cdots \int_{w_{n+1} \in K_{H}} M\left(K ; G\left(w_{1}\right), G\left(w_{2}\right), \cdots, G\left(w_{n+1}\right)\right) d w_{1} \cdots d w_{n+1} .
$$

(Since the integrand has been defined only if the intervals $K \cap G\left(w_{k}\right)$ have positive lengths and if the points $w_{k}$ are distinct, a set of measure 0 has been neglected.) Because of (18) with strict inequality for at least one system $w_{1}, w_{2}, \cdots, w_{n+1}$ and because of the continuity of the integrand in (19) (considered as a function of $w_{1}, w_{2}, \cdots, w_{n+1}$ ) the equation (19) implies that

$$
m_{r}(\widetilde{K}(H))<m_{r}(K) .
$$

This contradicts the assumption that $K$ be a minimum body for $m_{r}$. Therefore, only ellipsoids can be minimal bodies. Because of Lemma 1 and since $m_{r}$ is invariant under volume preserving affine transformations it follows that any sphere $S$ of unit volume is a minimal body, that

$$
m_{r}(S)<m_{r}(K)
$$

if $K$ is not an ellipsoid, and that

$$
m_{r}(S)=m_{r}(K)
$$

if $K$ is an ellipsoid. Hence, the Theorem is proved.

It might be worth noting that essentially the same method of proof can be used to establish a similar theorem with the higher order moments replaced by more general types of functions.

\section{REFERENCES}

1. W. Blaschke, Über affine Geometrie XI: Lösung des "Vierpunktproblems" von Sylvester aus der Theorie der geometrischen Wahrscheinlichkeiten, Ber. Verh. sächs. Akad. Leipzig, Bd. 69 (1971), 436-453.

2. - Vorlesungen über Differentialgeometrie II: Affine Differentialgeometrie, Springer, Berlin, 1923.

3. W. Blaschke, Kreis, und Kugel, Walter de Gruyter, Berlin, 1956.

4. T. Bonnesen and W. Fenchel, Theorie der konvexen Körper, Ergebn. d. Math. Bd. 3, Springer, Berlin, 1934 . 
5. L. Danzer, D. Laugwitz, and H. Lenz, Über das Löwnersche Ellipsoid und sein Analogon unter dem einem Eikörper einbeschriebenen Ellipsoiden, Arch. d. Math., 8 (1957), 214-219.

6. H. G. Eggleston, Convexity, Cambr. Tracts in Math., vol. 47, Cambridge University Press, Cambridge 1958.

7. H. Hadwiger, Vorlesungen über Inhalt, Oberfläche und Isoperimetrie, Grundl. d. math. Wiss., Bd. 93, Springer, Berlin-Göttingen-Heidelberg, 1957.

8. F. John, Extremum problems with inequalities as subsidiary conditions, Studies and essays presented to R. Courant, pp. 187-204, Interscience, New York, 1948.

9. M. G. Kendall and P.A.P. Moran, Geometrical Probability. Griffin, London, 1963.

10. J. F. C. Kingman, Random secants of a convex body, J. Appl. Prob., 6 (1969), 660-672.

11. V. Klee, What is the expected volume of a simplex whose vertices are chosen at random from a given convex body? Amer. Math. Monthly, 76 (1969), 286-288.

Received February 28, 1972 and in revised form May 11, 1972. This research was partially supported by NSF Grant GP-34002.

The University of ARIZona 



\section{PACIFIC JOURNAL OF MATHEMATICS}

\section{EDITORS}

\author{
H. SAMELson \\ Stanford University \\ Stanford, California 94305 \\ C. R. HоввY \\ University of Washington \\ Seattle, Washington 98105
}

J. DugundJI

Department of Mathematics

University of Southern California

Los Angeles, California 90007

RICHARD ARENS

University of California

Los Angeles, California 90024

\section{ASSOCIATE EDITORS}
E. F. BeCKENBACH
B. H. NEUMANN
F. WOLF
K. YoshidA

\section{SUPPORTING INSTITUTIONS}

UNIVERSITY OF BRITISH COLUMBIA

CALIFORNIA INSTITUTE OF TECHNOLOGY

UNIVERSITY OF CALIFORNIA

MONTANA STATE UNIVERSITY

UNIVERSITY OF NEVADA

NEW MEXICO STATE UNIVERSITY

OREGON STATE UNIVERSITY

UNIVERSITY OF OREGON

OSAKA UNIVERSITY

\author{
UNIVERSITY OF SOUTHERN CALIFORNIA \\ STANFORD UNIVERSITY \\ UNIVERSITY OF TOKYO \\ UNIVERSITY OF UTAH \\ WASHINGTON STATE UNIVERSITY \\ UNIVERSITY OF WASHINGTON

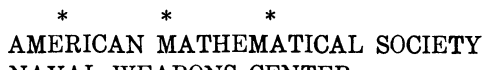 \\ NAVAL WEAPONS CENTER
}

The Supporting Institutions listed above contribute to the cost of publication of this Journal, but they are not owners or publishers and have no responsibility for its content or policies.

Mathematical papers intended for publication in the Pacific Journal of Mathematics should be in typed form or offset-reproduced, (not dittoed), double spaced with large margins. Underline Greek letters in red, German in green, and script in blue. The first paragraph or two must be capable of being used separately as a synopsis of the entire paper. The editorial "we" must not be used in the synopsis, and items of the bibliography should not be cited there unless absolutely necessary, in which case they must be identified by author and Journal, rather than by item number. Manuscripts, in duplicate if possible, may be sent to any one of the four editors. Please classify according to the scheme of Math. Rev. Index to Vol. 39. All other communications to the editors should be addressed to the managing editor, Richard Arens, University of California, Los Angeles, California, 90024.

50 reprints are provided free for each article; additional copies may be obtained at cost in multiples of 50 .

The Pacific Journal of Mathematics is issued monthly as of January 1966. Regular subscription rate: $\$ 48.00$ a year (6 Vols., 12 issues). Special rate: $\$ 24.00$ a year to individual members of supporting institutions.

Subscriptions, orders for back numbers, and changes of address should be sent to Pacific Journal of Mathematics, 103 Highland Boulevard, Berkeley, California, 94708.

PUBLISHED BY PACIFIC JOURNAL OF MATHEMATICS, A NON-PROFIT CORPORATION

Printed at Kokusai Bunken Insatsusha (International Academic Printing Co., Ltd.), 270, 3-chome Totsuka-cho, Shinjuku-ku, Tokyo 160, Japan. 


\section{Pacific Journal of Mathematics}

\section{Vol. 45, No. $2 \quad$ October, 1973}

Kenneth Paul Baclawski and Kenneth Kapp, Induced topologies for quasigroups and loops ............................................. 393

D. G. Bourgin, Fixed point and $\min -\max$ theorems $\ldots \ldots \ldots \ldots \ldots \ldots \ldots$

J. L. Brenner, Zolotarev's theorem on the Legendre symbol ............... 413

Jospeh Atkins Childress, Jr., Restricting isotopies of spheres .............. 415

John Edward Coury, Some results on lacunary Walsh series ................ 419

James B. Derr and N. P. Mukherjee, Generalized Sylow tower groups. II . . . . . . 427

Paul Frazier Duvall, Jr., Peter Fletcher and Robert Allen McCoy, Isotopy Galois

spaces .......................................... 435

Mary Rodriguez Embry, Strictly cyclic operator algebras on a Banach space ... 443

Abi (Abiadbollah) Fattahi, On generalizations of Sylow tower groups ......... 453

Burton I. Fein and Murray M. Schacher, Maximal subfields of tensor products . . 479

Ervin Fried and J. Sichler, Homomorphisms of commutative rings with unit

element .......................................... 485

Kenneth R. Goodearl, Essential products of nonsingular rings ............. 493

George Grätzer, Bjarni Jónsson and H. Lakser, The amalgamation property in

equational classes of modular lattices ...........................

507

$\mathrm{H}$. Groemer, On some mean values associated with a randomly selected simplex

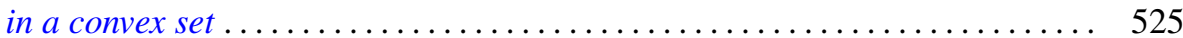

Marcel Herzog, Central 2-Sylow intersections .................... 535

Joel Saul Hillel, On the number of type-k translation-invariant groups ........ 539

Ronald Brian Kirk, A note on the Mackey topology for $\left(C^{b}(X)^{*}, C^{b}(X)\right) \ldots \ldots .543$

J. W. Lea, The peripherality of irreducible elements of lattice.............. 555

John Stewart Locker, Self-adjointness for multi-point differential operators ..... 561

Robert Patrick Martineau, Splitting of group representations ............... 571

Robert Massagli, On a new radical in a topological ring ................. 577

James Murdoch McPherson, Wild arcs in three-space. I. Families of Fox-Artin

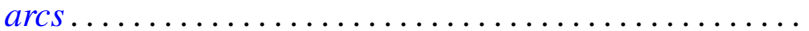

585

James Murdoch McPherson, Wild arcs in three-space. III. An invariant of

oriented local type for exceptional arcs . . . . . . . . . . . . ............ 599

Fred Richman, The constructive theory of countable abelian p-groups ........ 621

Edward Barry Saff and J. L. Walsh, On the convergence of rational functions

which interpolate in the roots of unity ..................

Harold Eugene Schlais, Non-aposyndesis and non-hereditary

decomposability..................................... 643

Mark Lawrence Teply, A class of divisible modules................... 653

Edward Joseph Tully, Jr., H-commutative semigroups in which each

homomorphism is uniquely determined by its kernel ................. 669

Garth William Warner, Jr., Zeta functions on the real general linear group ...... 681

Keith Yale, Cocyles with range $\{ \pm 1\} \ldots \ldots \ldots \ldots \ldots \ldots \ldots \ldots \ldots \ldots \ldots \ldots \ldots . \ldots \ldots$

Chi-Lin Yen, On the rest points of a nonlinear nonexpansive semigroup ........ 699 